\title{
Paste pipeline transportation for Chambishi Copper Mine
}

\author{
Hui Li NFC Africa Mining PLC, Zambia \\ Jinjun Zhang NFC Africa Mining PLC, Zambia \\ Donghong Zhang NFC Africa Mining PLC, Zambia \\ Zhanyan Li NFC Africa Mining PLC, Zambia \\ Guobin Hu NFC Africa Mining PLC, Zambia
}

\section{Abstract}

Due to its stability, fluidity, pumpability, energy-efficiency and environment-friendliness, paste filling has attracted an increasingly amount of attention in filling field worldwide. As one of the core technologies for paste filling system, pipeline transportation is affected by a number of factors. This paper mainly focuses on two, i.e. paste concentration and rheological characteristics. Based on the study of paste rheological properties and the industrial annulus test, the critical concentration of unclassified tailing is $69.1 \%$ and the recommended pipeline resistance is $4.0 \mathrm{MPa} / \mathrm{km}$ on pipeline design and equipment selection for Chambishi Copper Mine. This paper aims at providing a reference for similar paste backfilling design in other mines.

\section{Introduction}

Chambishi Mine, located in the center of Zambia Copper Belt, was previously attached to Zambia Consolidated Copper Mine Ltd. In 1998, After China and Zambia co-constructed the NFC Africa Mining PLC in 1998, the mine was put into operation again. Chambishi Mine consists of the Main orebody, West orebody and Southeast orebody. Among them, the production of the West orebody is $1.0 \mathrm{Mt}$ per year. The dip angle of the orebody is approximately $30^{\circ}$, the geology grade is $2.20 \%$ and the actual average thickness is $7.36 \mathrm{~m}$. The continuity of orebody is favorable and the extension is below $600 \mathrm{~m}$. The stability of the orebody itself is moderate but that of the rock is poor. The mine uses non-cemented classified tailings drift filling, during which a number of problems occur, including sludge disintegration with water, fragmentation of surrounding rock, outstanding ground pressure, low mining recovery, high dilution, etc. This leads to a serious waste of resources and reduces the life of mine. After technical verification and economic accounting, the paste filling system was introduced and successfully used in underground stope filling in 2013. Currently, the paste filling system is in steady operation, with stope conditions and main economic indicators having been greatly improved.

Without causing precipitation, segregation or dehydration, paste filling is known as a green mining technology in the twenty first century and has drawn an increasingly amount of attention in recent years. The core techniques of paste filling include flocculation thickening, stirring preparation, pipeline transportation and DCS control. Due to the stream structure of paste (Brackebusch, 1995; Belem and Benzaazoua, 2008). In the pipeline, theories and experiences regarding two-phase flow are insufficient for the application of paste pipeline transportation. This paper examines the theory and relevant formulas of 
paste pipeline transportation and hopes the optimization of pipeline design could ensure the steady and efficient operation of paste system.

\section{Basic properties of filling material}

Because of different metallogenic regularities, deposit properties and metal processing technologies, the characteristics of tailings produced vary greatly. As an important raw material for paste preparation, its basic physical performance determines the paste properties to some extent. Chambishi Copper Mine adopts tailings and cement as the paste preparation materials. Of the unclassified tailings, $70.845 \%$ are $-74 \mu \mathrm{m}$ whereas $46.975 \%$ are $-37 \mu \mathrm{m}$. The basic physical properties for unclassified tailing are as follows:

Table 1 Physical performance parameters of tailings

\begin{tabular}{cccc}
\hline Items & Density $\left(\mathrm{t} / \mathrm{m}^{3}\right)$ & Bulk density $\left(\mathrm{t} / \mathbf{m}^{\mathbf{3}}\right)$ & Porosity (\%) \\
\hline Data & 2.6705 & 1.392 & 47.9 \\
\hline
\end{tabular}

Table 2 Tailings grain level distribution (\%)

\begin{tabular}{cccccccc}
\hline $\mathbf{- 3 7} \boldsymbol{\mu \mathrm { m }}$ & $\mathbf{- 4 7} \boldsymbol{\mu \mathrm { m }}$ & $\mathbf{- 7 4} \boldsymbol{\mu \mathrm { m }}$ & $\mathbf{- 1 0 6} \boldsymbol{\mu \mathrm { m }}$ & $\mathbf{- 1 5 0} \boldsymbol{\mu \mathrm { m }}$ & $\mathbf{- 1 8 0} \boldsymbol{\mu \mathrm { m }}$ & $\mathbf{+ 1 8 0} \boldsymbol{\mu \mathrm { m }}$ & In total \\
\hline 46.975 & 6.37 & 17.495 & 16.575 & 8.26 & 3.985 & 0.335 & 99.995 \\
\hline
\end{tabular}

\section{Paste critical concentration of unclassified tailings}

To examine the unclassified tailings slurry, this research uses the Brookfield R/S+ rheometer to measure the rheological parameters for concentrations between 64 and 73\%. The rheological properties of slurry with different concentrations were analyzed to obtain the rheological model within a certain range of shear rate. Based on the model, the final paste critical concentration of unclassified tailings can be obtained.

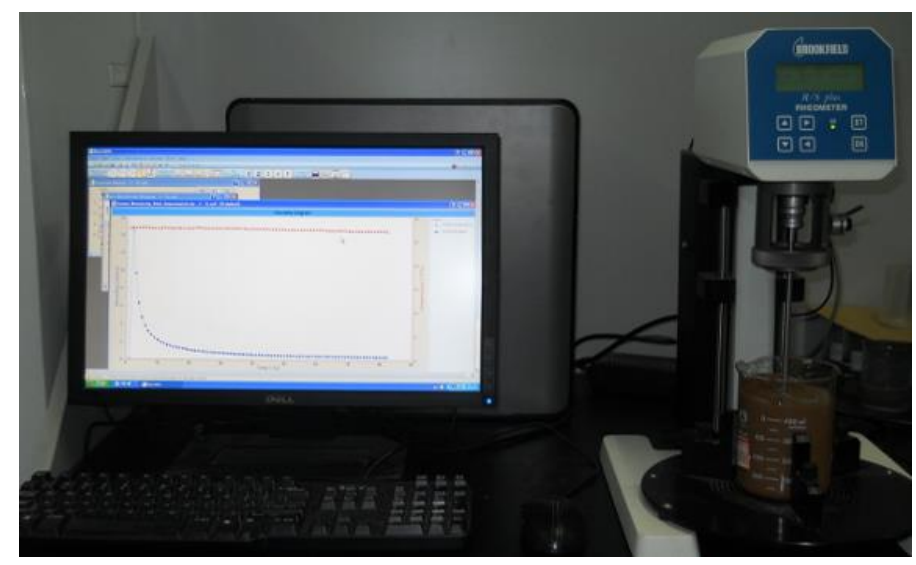

Figure 1 Brookfield R/S+ rheometer

\subsection{Experimental principles}

The dynamic rheological models mainly include Bingham model, Casson model and Herschel-Bulkey model. Among them, the Herschel-Bulkey model with three parameters has more value and wider application than the other two. The general Herschel-Bulkey model formula is as follows:

$$
\tau=\tau_{0}+\eta \gamma^{n}
$$

Where:

$\tau \quad=$ shear stress, $\mathrm{Pa}$; 


$$
\begin{aligned}
\tau_{0} & =\text { yield stress, } \mathrm{Pa} ; \\
\eta & =\text { viscosity coefficient, } \mathrm{Pa} \cdot \mathrm{s} ; \\
\nu & =\text { shear rate, } \mathrm{s}^{-1} ; \\
\mathrm{n} & =\text { fluid performance index; }
\end{aligned}
$$

When $\tau=u p, u$-apparent viscosity, Pa.s. Herschel-Bulkley model is used to analyze the performance index of slurry flow at different shear, and then the result of rheological model is obtained. When $n<1$, it is yield pseudo plastic body; When $n=1$, it is Bingham plastic body; When $n>1$, it is yield expansion body.

\subsection{Experimental contents}

Several samples of $300 \mathrm{~g}$ of slurry with different concentrations were prepared, stirred for approximately $5 \mathrm{~min}$ until uniform and then poured into $200 \mathrm{~mL}$ beakers separately. The stirring rotor (V40_20_3tol) was immersed into the slurry and placed under the rheometer to measure the yield stress and viscosity.

- The shear stress is slowly set from 0 to $300 \mathrm{~Pa}$; when the stirring rotor begins to rotate, the static yield stress can be obtained.

- The apparent viscosity and shear stress with different shear rate $\left(0 \mathrm{~s}^{-1}\right.$ to $\left.100 \mathrm{~s}^{-1}\right)$ are measured and the apparent viscosity and shear stress are regressed based on the Herschel-Bulkey model.

- The rheological curves (shear rate-shear stress) under different slurry concentrations are measured. Based on relevant calculations, the curve of $n$ value with different concentration is plotted. The nonlinear regression analysis is carried out and the concentration when $n=1$ is obtained, namely paste critical concentration.

\subsection{Results analysis}

The relevant curves of shear rate and shear stress with different slurry concentrations are plotted, as shown in Figure 2 .

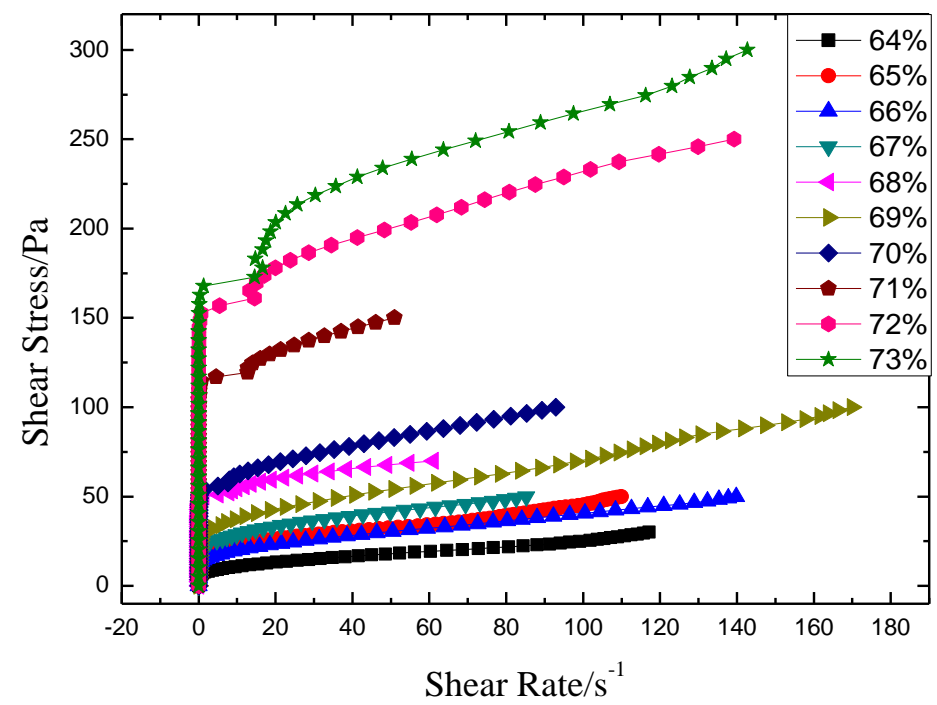

Figure 2 Shear rate and shear stress curve with different concentration

According to Figure 2, with the increase of shear rate, slurry structure will be destroyed and apparent viscosity reduces sharply. This phenomenon is more obvious with higher concentration and the rheological curve tends to the shear rate axis. With the continuous increase of shear rate, the slurry performance tends to be stable; the rule of apparent viscosity tending to decrease will be gentle and the final rule of shear rate and shear stress will be approximate to be linear.

Based on the Herschel-Bulkey model, the shear rate and shear stress curves are regressed and the yield stress, 
viscosity and fluid performance index are obtained.

Table 3 Regression result basing on the Herschel-Bulkey model

\begin{tabular}{ccccccccccc}
\hline Concentration (\%) & 64 & 65 & 66 & 67 & 68 & 69 & 70 & 71 & 72 & 73 \\
\hline Yield stress (Pa) & 15.05 & 19.18 & 27.39 & 34.07 & 34.5 & 34.77 & 62.44 & 109.4 & 145.44 & 159.25 \\
Plastic viscosity (Pa·s) & $7.00 \mathrm{E}-05$ & $1.04 \mathrm{E}-03$ & 0.01 & 0.029 & 0.31 & 0.34 & 0.42 & 2.1 & 4.34 & 8.06 \\
Fluid index & 2.58 & 2.11 & 1.57 & 1.415 & 1.21 & 1.03 & 0.99 & 0.76 & 0.65 & 0.57 \\
Correlation coefficient & 0.999 & 0.998 & 0.998 & 0.998 & 0.996 & 0.996 & 0.999 & 0.989 & 0.992 & 0.989 \\
\hline
\end{tabular}

According to the regression data of Table 3, plot the Figure of yield stress and slurry concentration.

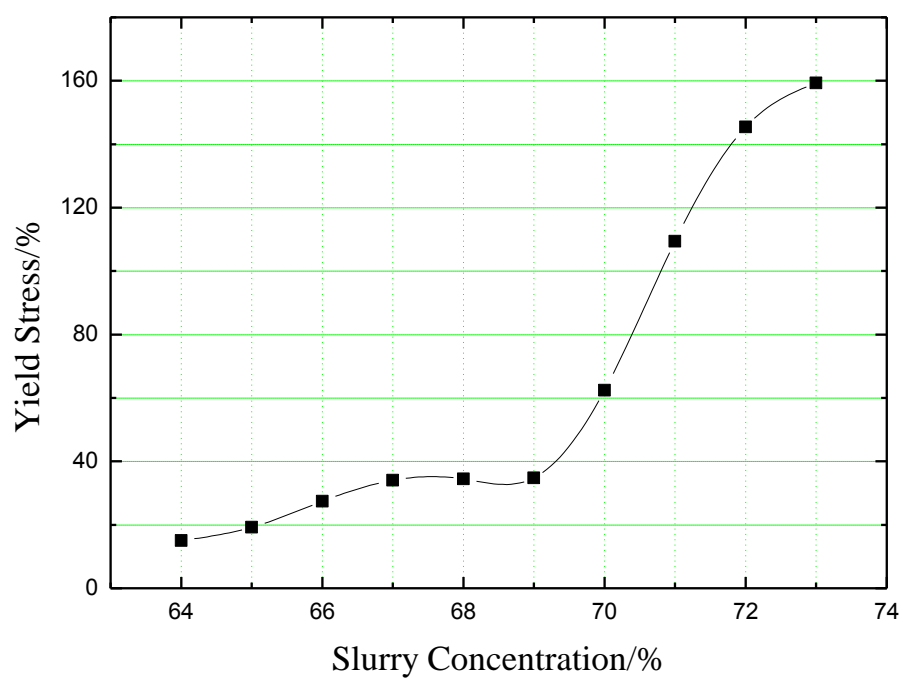

Figure 3 Yield stress and concentration relevant curve

According to Figure 3, when slurry concentration reaches $71 \%$, yield stress sharply increases from 62.44 to 109.40 Pa.

According to the regression data in Table 3 , the Figure of $n$ value and slurry concentration is obtained.

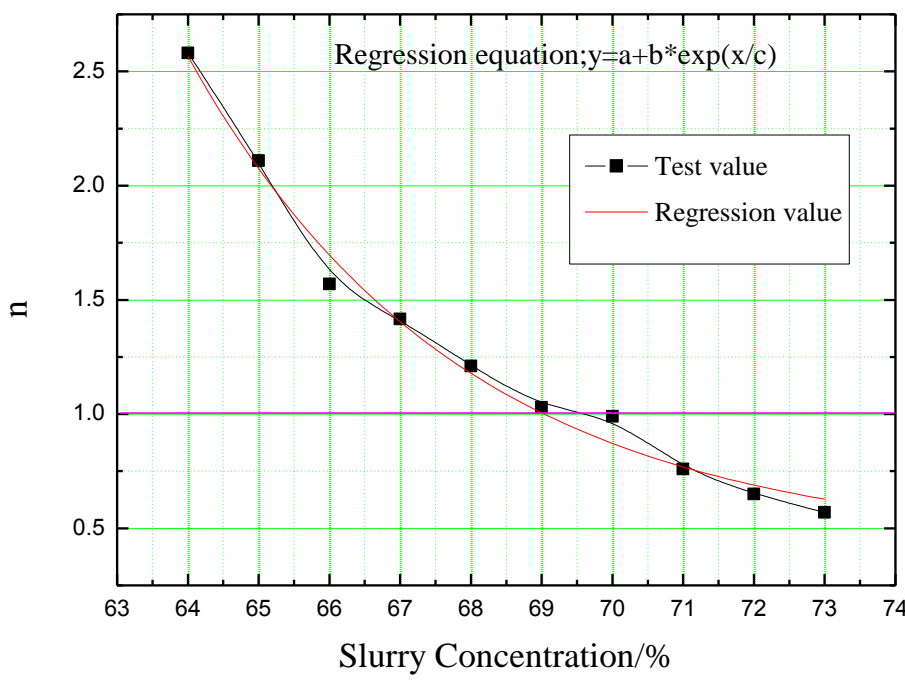

Figure $4 \quad \mathrm{~N}$ value and concentration relevant curve

According to Figure 4, the $\mathrm{n}$ value decreases monotonously with the increase of concentration and when the slurry concentration is between 69 and $70 \%$, the $n$ value is close to 1 . By the regression analysis, the paste critical concentration is $69.1 \%$. 


\section{$4 \quad$ Resistance analysis of paste pipeline transportation}

Based on the paste critical concentration, paste with different concentrations and cement ratios. When the cement ratio is between $1: 8$ and $1: 16$, the paste concentration is $68 \sim 72 \%$. The parameters with different paste concentrations and cement ratios are measured and the pipeline resistance parameter is calculated.

Compared with traditional classified tailings filling, paste slurry features high concentration and viscosity. Therefore, during pipeline transportation, the pipeline resistance is greater than the tradition method and if controlled improperly, accidents such as leakage and pipe breaking could happen. Meanwhile, pipeline resistance has an important practical value for the design and maintenance of pipe network system.

$$
i_{m}=\Delta P / l=\frac{4 \pi_{w}}{D}=\frac{16}{3 D} \cdot \tau_{0}+\frac{32 v}{D} \cdot \eta
$$

Where:

$$
\begin{array}{ll}
\tau_{0} & =\text { initial shear stress, } \mathrm{pa} ; \\
\eta & =\text { plastic viscosity coefficient, } \\
D & \text { Pa.s; } \\
v & =\text { pipe internal diameter, } \mathrm{m} ; \\
& =\text { average flow velocity, } \mathrm{m} / \mathrm{s} ;
\end{array}
$$

Table 4 Resistance calculation based on the paste rheological parameters

\begin{tabular}{lcccccc}
\hline No. & $\begin{array}{c}\text { Tailings concentration } \\
\text { (\%) }\end{array}$ & Cement ratio & $\begin{array}{c}\text { Paste concentration } \\
\text { (\%) }\end{array}$ & $\begin{array}{c}\text { Yield stress } \\
\text { (Pa) }\end{array}$ & $\begin{array}{c}\text { Viscosity } \\
\text { (Pa.s) }\end{array}$ & $\begin{array}{c}\text { Resistance } \\
\text { (MPa.km) }\end{array}$ \\
\hline N1 & 68 & $1: 8$ & 70.51 & 108.48 & 0.45 & 4.84 \\
N2 & 68 & $1: 12$ & 69.72 & 80.24 & 0.44 & 3.62 \\
N3 & 68 & $1: 16$ & 69.30 & 66.71 & 0.42 & 3.03 \\
N4 & 69 & $1: 8$ & 71.46 & 169.1 & 0.36 & 7.41 \\
N5 & 69 & $1: 12$ & 70.93 & 138.32 & 0.40 & 6.10 \\
N6 & 69 & $1: 16$ & 70.65 & 125.11 & 0.38 & 5.53 \\
N7 & 70 & $1: 8$ & 71.98 & 235.82 & 0.48 & 10.33 \\
N8 & 70 & $1: 12$ & 71.65 & 185.24 & 0.46 & 8.15 \\
N9 & 70 & $1: 16$ & 71.26 & 175.75 & 0.32 & 7.68 \\
\hline
\end{tabular}

Note: Pipe internal diameter $=124 \mathrm{~mm}$; Design filling capacity $=65 \mathrm{~m}^{3} / \mathrm{h}$.

Under the same tailings concentration, higher cement ratio leads to greater pipeline resistance. Furthermore, the increase of paste concentration also leads to greater pipeline resistance. When the filling capacity and pipe diameter remain the same, paste concentration with the same cement ratio of 1:8 increases from 70.51 to $71.98 \%$, with pipeline transportation resistance being more than doubled. When paste concentration stays within the range of $68^{\sim} 72 \%$, the pipeline transportation resistance is between 3.03 and $10.33 \mathrm{MPa} / \mathrm{km}$.

\section{$5 \quad$ Industrial test for pipeline transportation}

On the basis of the theoretical calculations above, pipeline transportation resistance with different paste concentration and cement ratio is measured by carrying out surface annulus test.

\subsection{Experiment scheme}

Considering the differences between theoretical calculation and industrial test and at the same time ensuring the successful operation of the text, the experiment uses the paste with a concentration of $65 \sim 71 \%$ and 
cement ratio of 1:6, 1:8 and 1:16. Pipe diameters are set to be 108, 124 and $\phi 150 \mathrm{~mm}$, with a total length of $80 \mathrm{~m}$. The rated flow rate of the plunger pump is $65 \mathrm{~m}^{3} / \mathrm{h}$ and the flow is controlled by pump speed $(20,40$, 60,80 and $100 \%$ ) during the test. In order to measure the pipe pressure, six pressure gauges are installed. During the test, the cement adding, paste mixing and the pump control and indication are controlled by DCS system.

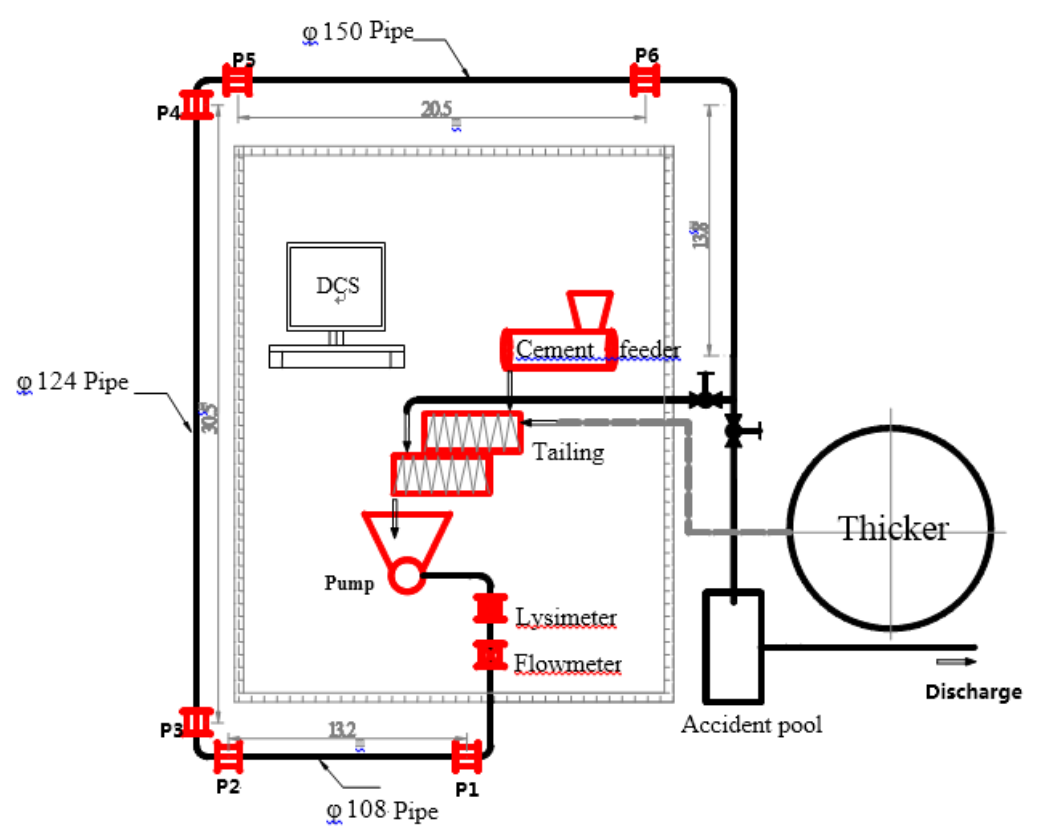

Figure 5 Pipeline installation and layout

\section{$5.2 \quad$ Results analysis}

(1) The resistance effect with different concentrations

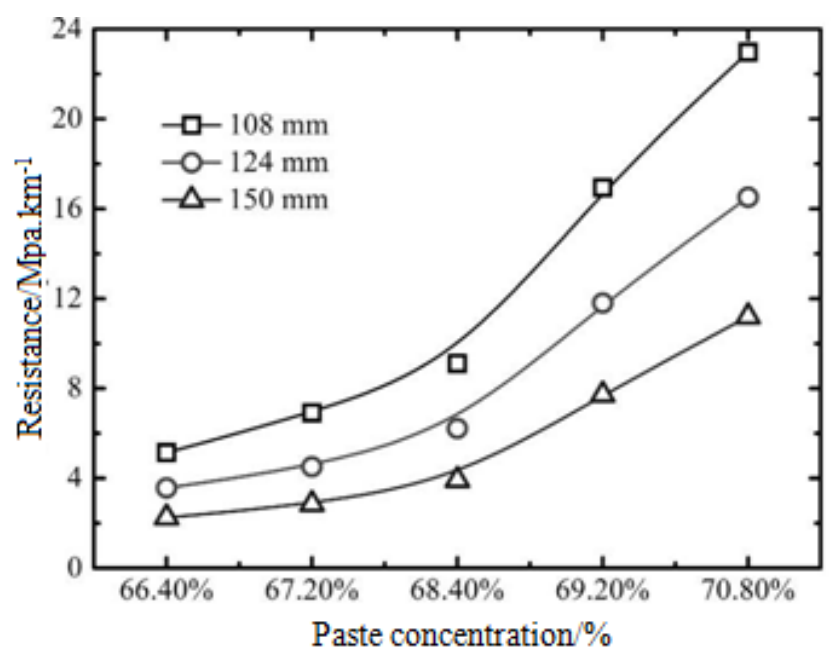

Figure 6 Resistance and concentration relevant curve

Slurry concentration has a significant impact on pipeline transportation resistance. With the increase of concentration by $1 \%$, pipeline resistance increases by 50 to $100 \%$. Especially when concentration is higher, the effect is more obvious. When pump speed is $100 \%$, that is, flow is $65 \mathrm{~m}^{3} / \mathrm{h}$, resistance increases with the paste concentration increasing. When concentration is blow $68.4 \%$, the increase of resistance is less obvious. However, when concentration is above $68.4 \%$, the increase of resistance is sharp. Considering the slight difference between the actual filling and industrial test, the normal filling concentration is suggested not to exceed $69 \%$. 
(2) The resistance effect with different cement ratio

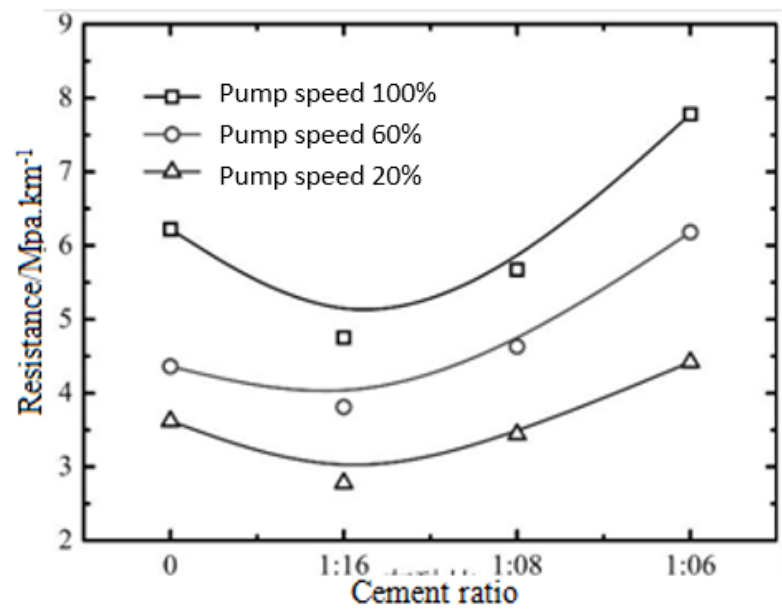

Figure 7 Resistance and cement ratio relevant curve

With the addition of cement, resistance first declines and then increases. The results show that cement can play a lubricating role in paste flow under a certain condition. However, slurry viscosity is also increased with more cement being added. When cement ratio exceeds $1: 12$, resistance gradually increases.

(3) The resistance effect with different pipe diameter

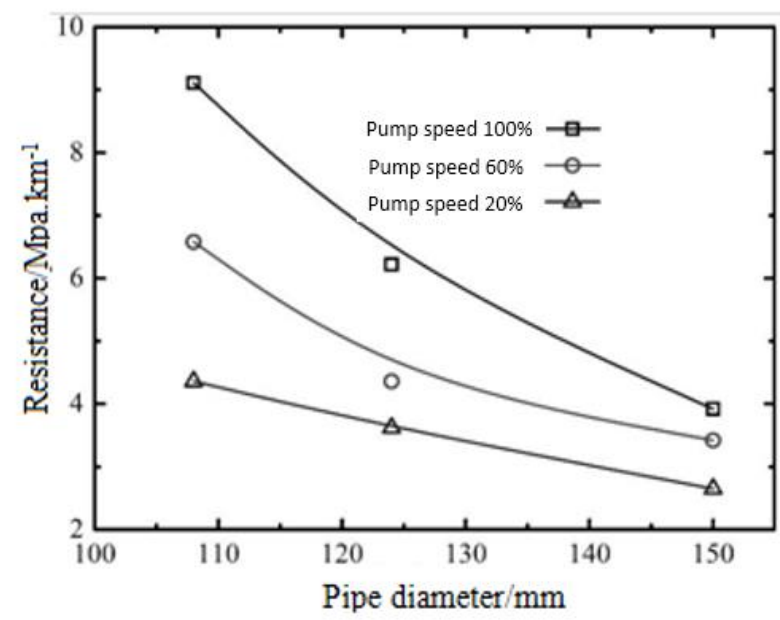

Figure 8 Resistance and pipe diameter relevant curve

With the pipe diameter increasing, pipeline transportation resistance decreases gradually based on the different pump speed, featuring an almost linear relation.

\subsection{Rheological parameter analysis}

Considering paste as Bingham fluid, the research used the test data of pressure and flow speed to calculate the rheological parameters. The data of pressure and flow speed are regressed with linear fitting formula when the pipe diameter is $124 \mathrm{~mm}$. The resumed regression formula is as follows:

$$
\mathrm{y}=a \mathrm{x}+\mathrm{b}
$$

According to the formula above, the equivalent is obtained:

$$
b=\frac{16}{3 D} \cdot \tau_{0} \rightarrow \tau_{0}=\frac{3 D}{16} \cdot b \quad a=\frac{32}{D^{2}} \cdot \eta \rightarrow \eta=\frac{D^{2}}{32} \cdot a
$$



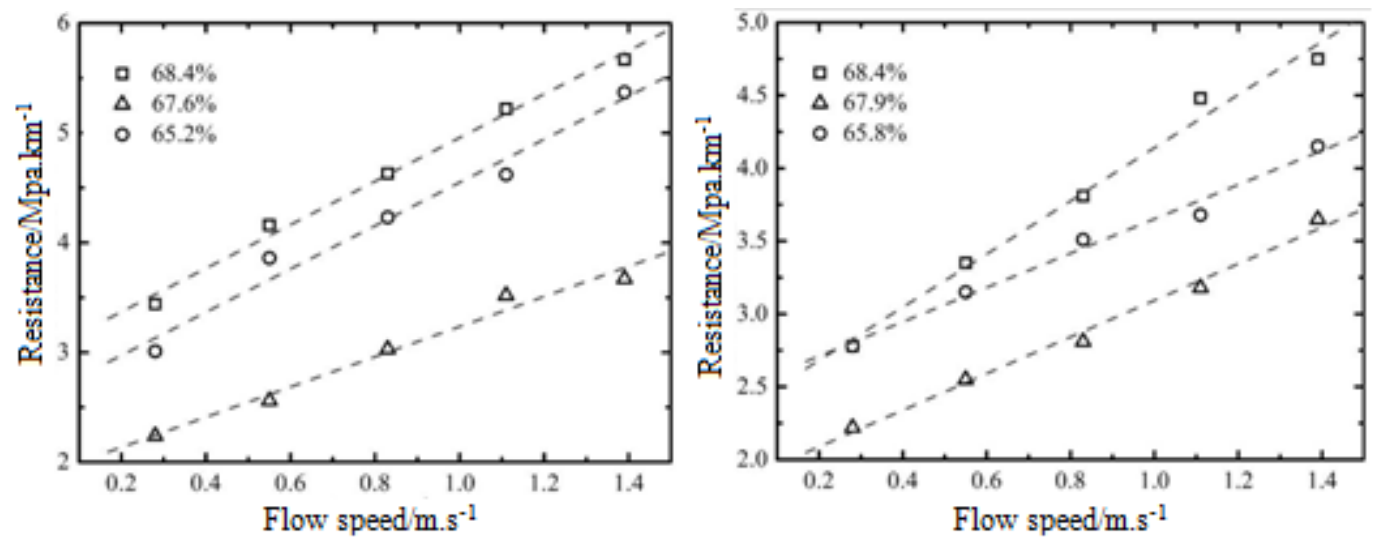

Figure 9 Resistance and flow speed relevant curve with cement ratio 1:8 and 1:16

Table 5 Calculation results of rheological parameters

\begin{tabular}{ccccccc}
\hline No. & $\begin{array}{c}\text { Paste } \\
\text { concentration (\%) }\end{array}$ & Cement ratio & $\mathbf{a}$ & $\mathbf{b}$ & $\boldsymbol{\tau}_{0}$ & $\boldsymbol{\eta}$ \\
\hline N4 & 68.4 & & 1.02 & 2.96 & 68.82 & 0.48 \\
N5 & 67.6 & $1: 8$ & 0.99 & 2.57 & 59.75 & 0.46 \\
N6 & 65.8 & & 0.69 & 1.85 & 43.01 & 0.33 \\
N7 & 68.4 & & 0.92 & 2.30 & 53.48 & 0.44 \\
N8 & 67.6 & $1: 16$ & 0.59 & 2.47 & 57.43 & 0.28 \\
N9 & 65.8 & & 0.64 & 1.83 & 42.55 & 0.31 \\
\hline
\end{tabular}

According to the regression data in Table 5, when paste concentration is $68.4 \%$ and filling capacity is $65 \mathrm{~m}^{3} / \mathrm{h}$ $\left(v=1.50 \mathrm{~m} / \mathrm{s}\right.$ ), pipeline transportation resistance of industrial test is $3.68^{\sim} 4.49 \mathrm{MPa} / \mathrm{km}$. Generally, the results of industrial tests, similar to actual filling process, are in good agreement with the theoretical values. Based on the underground backfilling requirements in Chambishi Mine, when cement ratio is 1:12 to 1:24 and paste concentration is approximately $69 \%$, paste pipeline transportation resistance is from 3.0 to 4.0 $\mathrm{MPa} / \mathrm{km}$. Pipeline transportation resistance is suggested to be $4.0 \mathrm{MPa} / \mathrm{km}$ on pipeline design and equipment selection.

\section{Conclusions}

Measuring the rheological properties of unclassified tailings with different concentrations, the paste critical concentration of unclassified tailings is obtained to be $69.1 \%$.

According to theoretical calculations, when paste concentration is controlled between 68 and $72 \%$, pipeline transportation resistance is between 3.03 to $10.33 \mathrm{MPa} / \mathrm{km}$.

Generally, the results of industrial tests, similar to actual filling process, are in good agreement with the theoretical values.

Based on the underground backfilling requirements in Chambishi Mine, when cement ratio is 1:12 to 1:24 and paste concentration is approximately $69 \%$, paste pipeline transportation resistance is from 3.0 to 4.0 $\mathrm{MPa} / \mathrm{km}$. Pipeline transportation resistance is suggested to be $4.0 \mathrm{MPa} / \mathrm{km}$ on pipeline design and equipment selection.

\section{References}

Belem, T. and Benzaazoua, M. 2008, 'Design and application of underground mine paste backfill technology', Geotechnical and Geological Engineering, vol. 26, no. 2, pp. 147-174.

Bloss, M.L. and Rankine, R. 2005, 'Paste fill operations and research at Cannington mine', The 9th Aus IMM Underground Operators' 
Conference, pp. 141-150.

Brackebusch, F.W. 1995, 'Basics of paste backfill systems', International Journal of Rock Mechanics and Mining Sciences and Geomechanics Abstracts. Elsevier Science, vol. 32, no. 3.

Wu, A.X., Yang, S.K., Wang H.J, Jiao H.Z. and Xiao Y.T. 2011, 'Chengkai etc. Super fine paste all end disposal technology', The Present Situation and Development Trend of Mining Technology, vol. 11, no. 3, pp. 4-8.

Zhang, K., Wang, C.L. and Huang, X.G. 2008, 'The paste pumping filling mining technology in the application of the huize lead-zinc deposit', Journal of Mining Technology, vol. 2, pp. 14-20. 